\title{
Spectroscopic Properties and Helical Stabilities of 25-nt Parallel-Stranded Linear DNA Duplexes
}

\author{
Karsten Rippe, ${ }^{\ddagger}$ Niels B. Ramsing, and Thomas M. Jovin* \\ Department of Molecular Biology, Max Planck Institute for Biophysical Chemistry, Postfach 2841, D-3400 Göttingen, FRG \\ Received April 12, 1989; Revised Manuscript Received July 12, 1989
}

\begin{abstract}
DNA strands with appropriate sequences of $\mathrm{dA}$ and $\mathrm{dT}$ can form a stable duplex in which the two strands adopt a parallel (ps) instead of the conventional antiparallel (aps) orientation. Four 25-nt $\mathrm{dA} \cdot \mathrm{dT}$-containing deoxyoligonucleotides (D1-4) were synthesized. D1 has the sequence $5^{\prime}$ $\mathrm{dA}_{10} \mathrm{TA}_{2} \mathrm{~T}_{4} \mathrm{~A}_{3} \mathrm{TAT}_{3}-3^{\prime}$. Viewed with the same polarity, D2, D3, and D4 are the complement, inverted complement, and inverse of D1, respectively. The two combinations D1.D3 and D2.D4 form conventional antiparallel duplexes (aps-D1·D3, aps-D2-D4). D1·D2 and D3·D4, however, constitute stable parallel-stranded duplexes (ps-D1·D2, ps-D3.D4), as established by various criteria including the following: (i) The electrophoretic mobilities of ps-D1.D2 and ps-D3.D4 are similar to those of the antiparallel-stranded duplexes. (ii) The ultraviolet absorption and circular dichroism spectra of the ps duplexes are indicative of a base-paired structure, but differ systematically from those of the aps helices. (iii) Similar salt-dependent thermal transitions are observed for the four duplexes, but the melting temperatures of the ps molecules are lower by $13-18^{\circ} \mathrm{C}$.
\end{abstract}

T he distinguishing features shared by the three major families of DNA duplexes, A-, B-, and Z-DNA, are the antiparallel orientation of the constituent strands and Watson-Crick base pairing. However, as reviewed elsewhere (Saenger, 1984; van de Sande et al., 1988), alternative conformations can be generated after certain chemical modifications of the bases or the sugar-phosphate backbone and/or by adjustments of the supporting electrolyte, e.g., to low $\mathrm{pH}$ values. Under physiological conditions, the only reported stable, alternative helical conformation involving two deoxyoligonucleotide strands with normal chemical composition is that of parallel-stranded DNA. In ps ${ }^{1}$-DNA, both strands have the same polarity and the secondary structure is maintained via reverse Watson-Crick base pairing. This structure was predicted by Pattabiraman (1986) from force field calculations and first verified experimentally by construction of hairpin molecules with altered phosphodiester bonds in the loops such that the strands in the stem are forced into a parallel orientation (van de Sande et al., 1988).

The construction of two-stranded ps-DNA duplexes requires selection of sequences that are perfectly complementary in the parallel orientation but which at the same time are poorly matched in all possible alternative, potentially competitive antiparallel homo- and heteroduplexes. A triad of 21-nt deoxyoligonucleotides ( $C$ series) was synthesized according to these criteria and provided the first evidence for ps-DNA duplexes arising from the spontaneous hybridization of two strands (Ramsing \& Jovin, 1988). Another linear ps molecule has been reported with one strand having overhanging $C$ tails to inhibit the formation of aps concatamers (Germann et al., 1988)

In the present study, a set of four 25-nt deoxyoligonucleotides (D series) was designed after further refinement of the sequence selection criteria to minimize the formation of antiparallel duplexes. Two pairs of ps and aps duplexes having the same nucleotide sequence were characterized with respect to spectroscopic, electrophoretic, ligand binding, and

\footnotetext{
* To whom correspondence should be addressed.

$\ddagger$ Work done as part of the Diplom degree, awarded by the University of Göttingen, FRG.
}

thermodynamic properties [which are also discussed in Ramsing et al. (1989)]. The comparative substrate properties of the ps and aps duplexes in various enzymatic and chemical reactions are reported in a companion paper (Rippe \& Jovin, 1989).

\section{Materials AND Methods}

Oligonucleotide Synthesis. The oligonucleotides D1-4 (Figure 1A) were synthesized by conventional phosphoramidite chemistry with an Applied Biosystems Model 381A DNA synthesizer. Purification was by chromatography with an LKB-Pharmacia FPLC system on (i) a ProRPC HR5/10 reversed-phase column before detritylation (gradient used was $5-42 \% \mathrm{CH}_{3} \mathrm{CN} / 0.1 \mathrm{M}$ TEAA, $\mathrm{pH} 7.0$, in $40 \mathrm{~min}$ at 0.5 $\mathrm{mL} / \mathrm{min}$ ), followed by a run on (ii) a Mono Q HR5/5 anion-exchange column after detritylation (gradient used was $0.45-0.90 \mathrm{M} \mathrm{NaCl} / 10 \mathrm{mM} \mathrm{NaOH}, \mathrm{pH} 12.0$, in $50 \mathrm{~min}$ at 0.5 $\mathrm{mL} / \mathrm{min}$ ).

Oligonucleotide concentrations are expressed in molar base units unless otherwise indicated. All solutions contained as standard buffer $10 \mathrm{mM}$ sodium cacodylate, $\mathrm{pH} 7.1$, in addition to the specified salts $\left(\mathrm{NaCl}, \mathrm{MgCl}_{2}\right)$. The molar extinction coefficient of the oligonucleotides was taken to be $8.6 \mathrm{mmol}$ base $\mathrm{cm}^{-1} \mathrm{~cm}^{-1}$ at $264 \mathrm{~nm}$ in the denatured state $\left(70^{\circ} \mathrm{C}\right.$ standard buffer plus $0.1 \mathrm{M} \mathrm{NaCl}$ ) as determined before by phosphate and spectroscopic analysis with the $\mathrm{C}$ series (Ramsing \& Jovin, 1988). The wavelength of $264 \mathrm{~nm}$ was chosen to compensate for the different ratios of $\mathrm{dA}$ and $\mathrm{dT}$, because it corresponds to an isosbestic point for poly (dA) and poly(dT) under approximately the same conditions (Riley et al., 1966). DNA duplexes were prepared by mixing the desired oligonucleotides in the specified salt solutions, heating to $50-60^{\circ} \mathrm{C}$ for $5 \mathrm{~min}$, and cooling slowly to room temperature.

Gel Electrophoresis. The oligonucleotides and their complexes were examined by polyacrylamide gel electrophoresis under two conditions: (i) denaturing, with $20 \%$ polyacrylamide (5\% cross-linking), $8 \mathrm{M}$ urea, $90 \mathrm{mM}$ Tris-borate, and $2 \mathrm{mM}$

\footnotetext{
${ }^{1}$ Abbreviations: ps, parallel-stranded; nt, nucleotide; aps, antiparallel-stranded; ss, single-stranded; FPLC, fast protein liquid chromatography; TEAA, triethylammonium acetate; $C D$, circular dichroism. 
A

D1: 5 '-AAAAAAaAaAtaAtTtTAAatATtT-3'

D2: 5'-TTTTTTTTTTATTAAAATtTATAAA-3'

D3: 5'-AaAtattTAaAatTATtTTtTTtTT-3'

D4: 5'-TTTATAAATtTTAATAAAAAAAAAA-3'

B

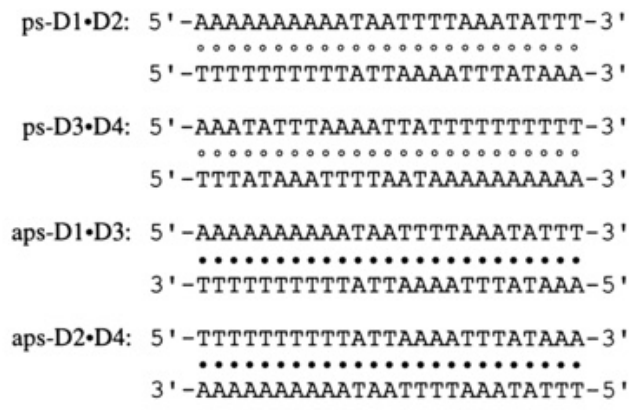

C

aps-D1•D1: 5 '-AAAAAAAAAATAATTTTAAATATTT - 3 '

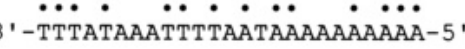

aps-D1•D2: 5 '-AAAAAAAAAATAATTTTAAATATTT - 3 ' - $\cdots$. $\cdots$. . .

3'-AAATATTTAAAATTATTTTTTTTTT-5'

FIGURE 1: Sequences of oligonucleotides and their duplexes. (A) Oligonucleotides D1-4. (B) Combinations of D1-4 that form perfectly matched ps and aps duplexes. The Watson-Crick base pairs of the antiparallel duplex aps-D1.D3 are shown by the symbol $\bullet$ and the reverse Watson-Crick base pairs of the parallel-stranded duplexes (ps-D1·D2, ps-D3.D4) by the symbol O. (C) Potentially competitive antiparallel secondary structures. An aps-D1.D1 homoduplex having 14 base pairs and an aps-D1.D2 heteroduplex having 11 base pairs are shown.

NaEDTA, $\mathrm{pH} 8.0,70^{\circ} \mathrm{C}$; (ii) native, with $14 \%$ polyacrylamide (5\% cross-linking), $90 \mathrm{mM}$ Tris-borate, and $2 \mathrm{mM} \mathrm{MgCl}$, $\mathrm{pH} 8.0,20^{\circ} \mathrm{C}$. The oligonucleotides were end labeled with ${ }^{32} \mathrm{P}$ to a specific activity of $10^{5} \mathrm{cpm} / \mathrm{nmol}$ with $\mathrm{T} 4$ polynucleotide kinase (New England Biolabs); the labeled molecules are designated with an asterisk in the text and figure legends. Autoradiographs from radiolabeled samples were photographed with a TV camera. The images were digitized and processed by logarithmic conversion and integration over the individual spot densities.

Spectroscopy. Ultraviolet absorption measurements were made with a Uvikon 820 spectrophotometer equipped with computer-controlled thermostated cuvette holders and data acquisition. Spectra were recorded in steps of $2 \mathrm{~nm}$ from 220 to $320 \mathrm{~nm}$ in $4 \mathrm{~mm}$ (width) $\times 1 \mathrm{~cm}$ (path length) cuvettes at $4^{\circ} \mathrm{C}$ intervals for both heating and cooling cycles in the range from 2 to $96^{\circ} \mathrm{C}$. Thermal equilibration was achieved in $2 \mathrm{~min}$, and a further 4 min was used to obtain chemical equilibrium indicated by stabilization of the absorbance. The data sets were corrected and analyzed according to procedures described elsewhere (Ramsing et al., 1989). The spectra were plotted with the ICEX GRAFkit graphics program implemented on a DEC MicroVax II computer. Circular dichroism (CD) spectra were acquired on a Jobin Yvon Model IV dichrograph in $2 \mathrm{~mm}$ (width) $\times 10 \mathrm{~mm}$ (path length) cuvettes and with a resolution of $1 \mathrm{~nm}$.

\section{Results AND Discussion}

Design of Oligonucleotides. Four 25-nt sequences (D1-4, Figure 1A) were designed to form perfect ps (ps-D1.D2, psD3.D4, Figure 1B) and corresponding aps (aps-D1·D3, aps-

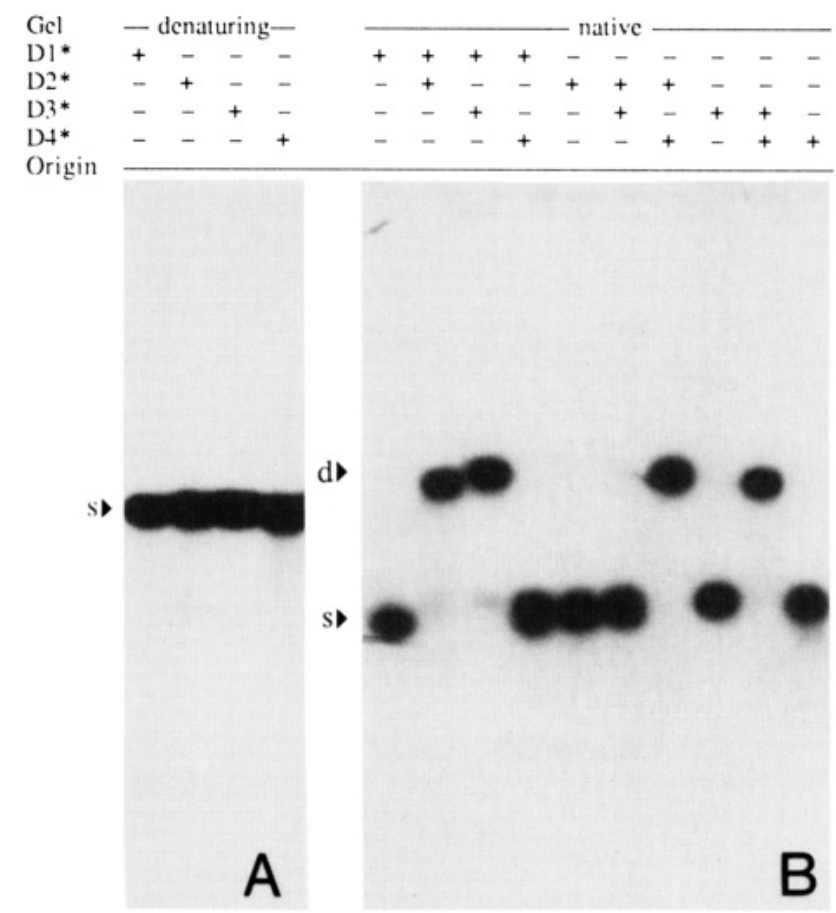

FIGURE 2: Electrophoretic analysis of oligonucleotides and duplex formation. (A) Autoradiograph of ${ }^{32} \mathrm{P}$-labeled $\mathrm{D} 1^{*}-4^{*}$, run on a denaturing $20 \%$ polyacrylamide gel at $70^{\circ} \mathrm{C}$. (B) Native gel with $2 \mathrm{mM} \mathrm{MgCl}_{2}$ at $20^{\circ} \mathrm{C}$ of the different combinations of $\mathrm{Dl}^{*}-4^{*}$. The positions of the single-stranded and duplex molecules are indicated by the letters $s$ and $d$.

D2.D4, Figure 1B) duplexes with the same nucleotide sequences. The sequences were selected by generating all possible unique combinations of dA and dT in a 25 -nt segment and choosing those optimal with respect to the following criteria: (i) minimal base-pairing potential considering continuous as well as interrupted runs in the aps heteroduplex which could arise from the two strands selected for the ps duplex [an aps-D1.D2 heteroduplex with the maximal number of base pairs (11) is shown in Figure 1C]; (ii) minimal base pairing of the aps homoduplex [an aps-D1.D1 homoduplex with the maximal number of potential base pairs (14) is shown in Figure 1C]; and (iii) minimal tendency to form concatamers by sequence overlaps. In addition, the sequences were also selected so as to contain recognition sites for restriction endonucleases.

Electrophoretic Properties. The individual oligonucleotides and their aps and ps duplexes were characterized by polyacrylamide gel electrophoresis. The purity of the isolated end-labeled oligonucleotides was established by electrophoresis under denaturing conditions (Figure 2A). No contaminating faster or slower migrating species could be detected.

The generation and stability of duplex structures were examined by gel electrophoresis. The only duplexes formed were ps-D1·D2, ps-D3·D4, and the corresponding aps-D1·D3 and aps-D2-D4, all of which had similar electrophoretic mobilities (Figure 2B). However, the ps species consistently had 5\% higher mobilities than their aps counterparts, a finding also observed previously with the C series (Ramsing \& Jovin, 1988) as well as with other ps-DNA constructs (van de Sande et al., 1988; Germann et al., 1988).

The formation and stoichiometries of the parallel-stranded ps-D1*.D2, ps-D3*.D4, and aps-D2*.D4 duplexes were demonstrated in a titration experiment (Figure 3). The ${ }^{32} \mathrm{P}$-labeled oligonucleotide shifted from a migration position corresponding to the single-stranded form to that of the double-stranded duplex upon addition of the corresponding complementary 

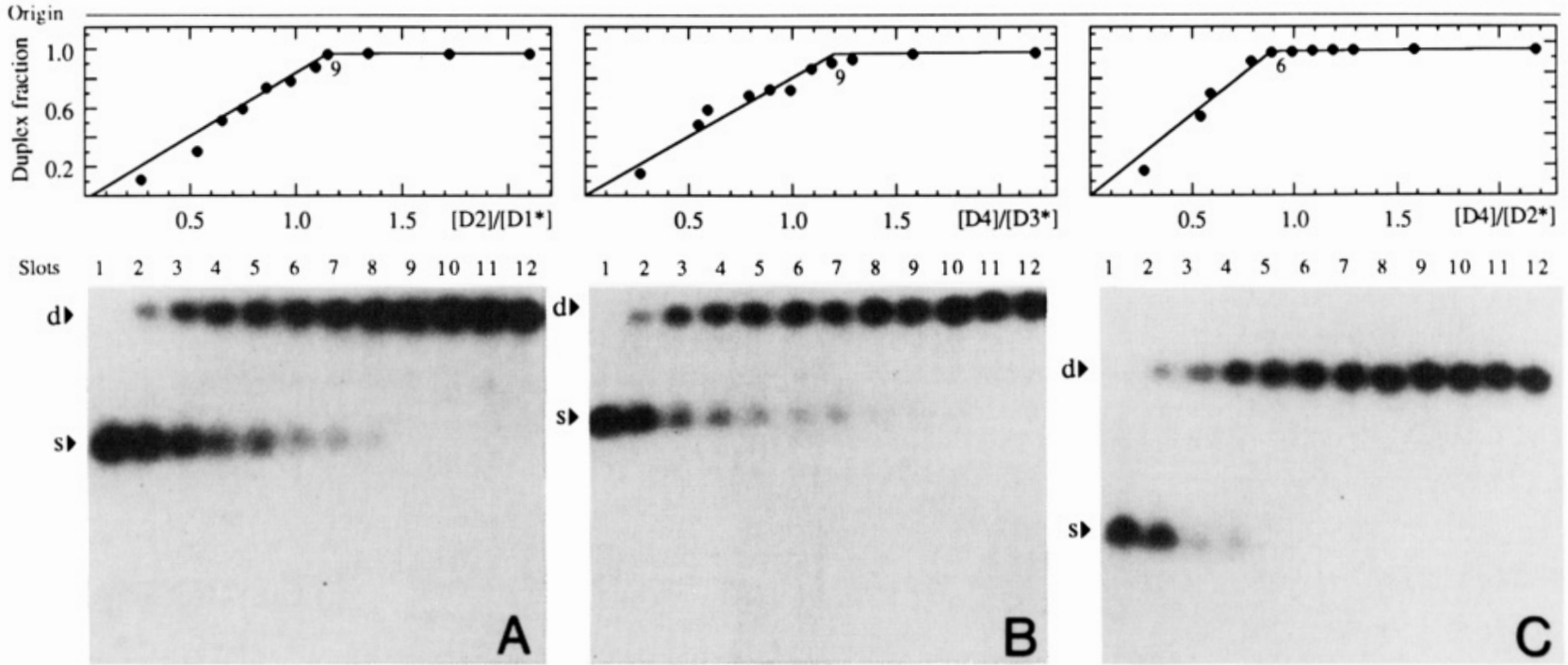

FIGURE 3: Titrations of radiolabeled $\mathrm{D} 1{ }^{*}, \mathrm{D} 3^{*}$, and $\mathrm{D} 2{ }^{*}$ with unlabeled complementary oligonucleotides. The ${ }^{32} \mathrm{P}$-labeled oligonucleotides (titrated species) were at $100 \mu \mathrm{M}$ in $10 \mathrm{mM}$ sodium cacodylate, $\mathrm{pH} 7.1,10 \mathrm{mM} \mathrm{NaCl}$, and $2 \mathrm{mM} \mathrm{MgCl}$. After the given amount of unlabeled oligonucleotide (titrant) was added, the solutions were heated to $60^{\circ} \mathrm{C}$ for $5 \mathrm{~min}$, allowed to cool slowly to $25^{\circ} \mathrm{C}$, and applied to a native $14 \%$ polyacrylamide gel at $20^{\circ} \mathrm{C}$. The concentration of the titrant in lanes $1-12$ was, respectively, $0,28,57,68,79,91,102,114,125,136$, 170 , and $227 \mu \mathrm{M}$. The positions of the single-stranded and duplex molecules are indicated by the letters $\mathrm{s}$ and $\mathrm{d}$. The autoradiographs of the gel were digitized and processed so as to obtain the integrated optical density for each spot from which the fractional content of the duplex was determined. (A) D1* titrated with D2. The duplex fraction of ps-D1*.D2 is plotted as a function of the strand concentration ratio D2/D1*. (B) D3* titrated with D4. The duplex fraction of ps-D3*.D4 is plotted as a function of the strand concentration ratio D4/D3*. (C) D2* titrated with D4. The duplex fraction of aps-D2*.D4 is plotted as a function of the strand concentration ratio D4/D2*.

unlabeled oligonucleotide. All titrations showed equivalence points between 0.9 and 1.2 , demonstrating the duplex nature of both the ps and the aps structures, i.e., a 1:1 stoichiometry with no indication of higher order species (Figure 3). However, in the case of both ps titrations, the observed equivalence point was somewhat higher than in the aps experiment, probably reflecting the reduced helical stability of the ps-DNA duplexes (see below) and a consequent reequilibration during electrophoresis.

Spectroscopic Properties of the ps and aps Duplexes. The ultraviolet absorption spectra of ps-D1.D2 and ps-D3.D4 at $10^{\circ} \mathrm{C}$ in both $\mathrm{MgCl}_{2}$ and $\mathrm{NaCl}$ solutions were different from those of the corresponding control aps-D1.D3 and aps-D2.D4 (Figure 4A-C). The difference spectra (ps - aps) had the following characteristic features (Figure 4D-F): a positive peak at $250-255 \mathrm{~nm}$, a negative peak at $280-285 \mathrm{~nm}$, and an isosbestic point at $270 \mathrm{~nm}$. The blue shift in the ultraviolet absorption spectrum of the ps helix is particularly evident in the pattern of hyperchromicity accompanying denaturation, expressed as the ratio of the absorbance at $70^{\circ} \mathrm{C}$ to that at $10^{\circ} \mathrm{C}$ (Figure $4 \mathrm{G}-\mathrm{I}$ ). This pattern was the same as that observed previously for the hairpins with $\mathrm{dA}_{10} \cdot \mathrm{dT}_{10}$ stems and the C-series duplexes (Ramsing et al., 1989). As expected, the ultraviolet spectra under denaturing conditions $\left(70^{\circ} \mathrm{C}\right.$, Figure $4 \mathrm{~A}-\mathrm{C}$ ) were nearly identical for the four oligonucleotides D1-4.

The ps-D3·D4 and aps-D2-D4 duplexes were also analyzed by circular dichroism (CD) spectroscopy (Figure 5). The dichroism of the ps duplex was slightly higher at the positive maximum $220 \mathrm{~nm}$ but lower at longer wavelengths, a result also obtained previously with the hairpin molecules and the $\mathrm{C}$-series duplexes. The salt-dependent features observed in the primary spectra were not apparent in the difference $C D$ (Figure $5 \mathrm{C}$ ). For both the $\mathrm{MgCl}_{2}$ and $\mathrm{NaCl}$ solutions the spectra were characterized by positive peaks near 215 and 250 $\mathrm{nm}$ and negative peaks at $230-240$ and $280 \mathrm{~nm}$.

Thermodynamic Properties of the ps and aps Duplexes. We recorded the thermal transitions as a set of tempera- ture-dependent absorption spectra. The absorbances at each temperature $T$ were normalized to the values at the initial (low) temperature $T_{0}$ (Figure 6). The resultant three-dimensional plots obtained in this manner are diagnostic for different DNA conformations (N. B. Ramsing and T. M. Jovin, unpublished data). Each data set was corrected for contributions of buffer absorbance, thermal expansion, and discrepancies between cuvettes (Ramsing et al., 1989). All duplexes exhibited a hyperchromicity in the ultraviolet absorption spectrum as expected for an endothermic cooperative transition from a base-stacked double-stranded structure to the random coil. The hyperchromicity spectra of the ps and aps helices (Figure 6) revealed the same striking differences obtained before with both the C-series duplexes and the hairpins. Whereas ps-D1·D2 and ps-D3.D4 in either $\mathrm{MgCl}_{2}$ or $\mathrm{NaCl}$ solutions had a peak near $270 \mathrm{~nm}$, the corresponding aps-D1-D3 and aps-D2.D4 duplexes showed a plateau in the range 240-270 $\mathrm{nm}$. Within the ps and the aps groups, the pattern of hyperchromicity in $\mathrm{NaCl}$ as well as in $\mathrm{MgCl}_{2}$ was nearly identical for each of the two member duplexes. All species demonstrated reversible thermal transitions.

The data from experiments under various ionic conditions were compatible with an all- or-none two-state model for the helix-coil transition, a detailed analysis of which is given in Ramsing et al. (1989). The values determined for $T_{\mathrm{m}}$ were slightly dependent on the direction of the thermal transition. That is, the $T_{\mathrm{m}}$ calculated from the descending limb was $\sim 0.3$ ${ }^{\circ} \mathrm{C}$ higher than the corresponding value from the ascending segment, probably due to evaporation during heating. Therefore, only the absorbance values obtained from the initial heating cycle of the thermal melting profile were used in the determinations of $T_{\mathrm{m}}$. The van't Hoff enthalpy difference for the helix-coil transition, $\Delta H_{\mathrm{vH}}$, was found not to be correlated with the direction of the transition and was also independent of $\mathrm{NaCl}$ and $\mathrm{MgCl}_{2}$ concentration in the range $0.1-1.0 \mathrm{M}$ and $0.5-8 \mathrm{mM}$, respectively.

We note from Figure 7 and Table I that (i) both members of each ps-DNA and aps-DNA class had similar thermody- 

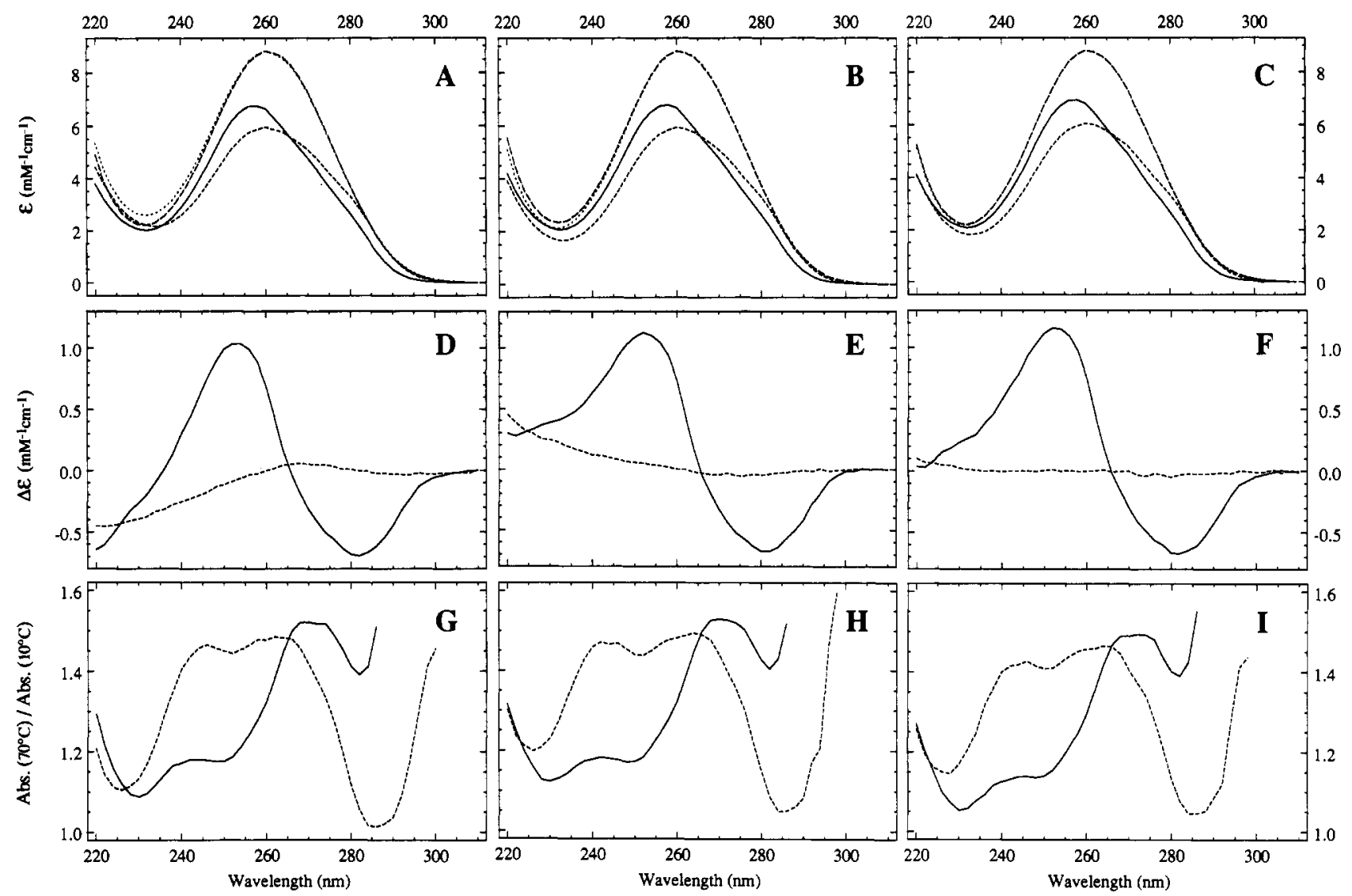

FIGURE 4: Ultraviolet absorption spectra of ps and aps oligonucleotides. (A, D, G) ps-D1.D2 and aps-D1.D3 in $2 \mathrm{mM} \mathrm{MgCl} 2$ and $10 \mathrm{mM}$ sodium cacodylate, pH 7.1. (B, E, H) ps-D3.D4 and aps-D2.D4 in $2 \mathrm{mM} \mathrm{MgCl}$ and $10 \mathrm{mM}$ sodium cacodylate, pH 7.1. (C, F, I) ps-D3.D4 and aps-D2.D4 in $0.1 \mathrm{M} \mathrm{NaCl}$ and $10 \mathrm{mM}$ sodium cacodylate, $\mathrm{pH} 7.1$. (A-C) UV spectra at $10^{\circ} \mathrm{C}$, ps duplexes (-) and aps duplex (---), and at $70^{\circ} \mathrm{C}$, melted ps duplexes $(--)$ and melted aps duplexes $(\cdots)$. (D-F) Difference spectra (ps - aps) at $10^{\circ} \mathrm{C}(-)$ and at $70^{\circ} \mathrm{C}(\cdots)$. (G-I) Hyperchromicity spectra of ps duplexes (-) and aps duplexes (-.-).

Table I: Thermodynamic Parameters for Helix-Coil Transition ${ }^{a}$

\begin{tabular}{|c|c|c|c|c|c|c|c|c|c|c|c|c|c|c|}
\hline \multirow[b]{3}{*}{ duplex } & \multicolumn{7}{|c|}{$\mathrm{NaCl}$} & \multicolumn{7}{|c|}{$\mathrm{MgCl}_{2}$} \\
\hline & \multicolumn{4}{|c|}{ total } & \multicolumn{3}{|c|}{ per $\mathbf{N N}^{b}$} & \multicolumn{4}{|c|}{ total } & \multicolumn{3}{|c|}{ per NN } \\
\hline & $\begin{array}{c}T_{\mathrm{m}}{ }^{\mathrm{e}} \\
\left({ }^{\circ} \mathrm{C}\right)\end{array}$ & $\begin{array}{c}\Delta H_{\mathrm{vH}}{ }^{d} \\
(\mathbf{k J} \\
\left.\mathrm{mol}^{-1}\right)\end{array}$ & $\begin{array}{c}\Delta S^{e}(\mathrm{~kJ} \\
\left.\mathrm{mol}^{-1} \mathrm{~K}^{-1}\right)\end{array}$ & $\begin{array}{c}\Delta G^{f} \\
(\mathrm{~kJ} \\
\left.\mathrm{mol}^{-1}\right)\end{array}$ & $\begin{array}{c}\Delta h \\
(\mathrm{~kJ} \\
\left.\mathrm{mol}^{-1}\right)\end{array}$ & $\begin{array}{c}\Delta s(\mathrm{~J} \\
\left.\mathrm{mol}^{-1} \mathrm{~K}^{-1}\right)\end{array}$ & $\begin{array}{c}\Delta \mathrm{g} \\
(\mathrm{kJ} \\
\left.\mathrm{mol}^{-1}\right)\end{array}$ & $\begin{array}{c}T_{\mathrm{m}}^{g} \\
\left({ }^{\circ} \mathrm{C}\right)\end{array}$ & $\begin{array}{c}\Delta H_{\mathrm{vH}}{ }^{h} \\
(\mathrm{~kJ} \\
\left.\mathrm{mol}^{-1}\right)\end{array}$ & $\begin{array}{c}\Delta S^{i}(\mathrm{~kJ} \\
\left.\mathrm{mol}^{-1} \mathrm{~K}^{-1}\right)\end{array}$ & $\begin{array}{c}\Delta G^{j} \\
(\mathbf{k J} \\
\left.\mathrm{mol}^{-1}\right)\end{array}$ & $\begin{array}{c}\Delta h \\
(\mathrm{~kJ} \\
\left.\mathrm{mol}^{-1}\right)\end{array}$ & $\begin{array}{c}\Delta s(\mathbf{J} \\
\left.\mathrm{mol}^{-1} \mathrm{~K}^{-1}\right)\end{array}$ & $\begin{array}{c}\Delta g \\
(\mathrm{~kJ} \\
\left.\mathrm{mol}^{-1}\right)\end{array}$ \\
\hline $\begin{array}{l}\text { ps-D1·D2 } \\
\text { ps-D3·D4 } \\
\text { aps-D1·D3 } \\
\text { aps-D2.D4 }\end{array}$ & $\begin{array}{l}29.0 \\
28.9 \\
46.4 \\
43.4\end{array}$ & $\begin{array}{l}459 \\
507 \\
670 \\
628\end{array}$ & $\begin{array}{l}1.40 \\
1.56 \\
1.97 \\
1.86\end{array}$ & $\begin{array}{l}42 \\
42 \\
80 \\
72\end{array}$ & $\begin{array}{l}19 \\
21 \\
28 \\
26\end{array}$ & $\begin{array}{l}58 \\
65 \\
82 \\
78\end{array}$ & $\begin{array}{l}1.7 \\
1.7 \\
3.3 \\
3.0\end{array}$ & $\begin{array}{l}35.7 \\
36.6 \\
50.8 \\
49.6\end{array}$ & $\begin{array}{l}507 \\
542 \\
736 \\
669\end{array}$ & $\begin{array}{l}1.52 \\
1.63 \\
2.15 \\
1.95\end{array}$ & $\begin{array}{l}53 \\
56 \\
94 \\
87\end{array}$ & $\begin{array}{l}21 \\
23 \\
31 \\
28\end{array}$ & $\begin{array}{l}63 \\
68 \\
90 \\
81\end{array}$ & $\begin{array}{l}2.2 \\
2.3 \\
3.9 \\
3.6\end{array}$ \\
\hline
\end{tabular}

a Thermodynamic measurements in $10 \mathrm{mM}$ sodium cacodylate, $\mathrm{pH} 7.1$, and increasing concentrations of added salt in the experimental ranges $0.05-1.6 \mathrm{M}$ $\mathrm{NaCl}$ and $0.05-8 \mathrm{mM} \mathrm{MgCl}$ (see also Figure 7). Experimental quantities determined at different DNA concentrations were recalculated for a total strand concentration of $1.6 \mu \mathrm{M}$. The listed values are the averages from numerous measurements, the $95 \%$ confidence limits of which were $<5 \%$ of the means [see also Ramsing et al. (1989)]. ${ }^{b}$ Total values divided per nearest-neighbor interactions (NN), $n-1=24 .{ }^{\circ} T_{\mathrm{m}}$ in $0.1 \mathrm{M} \mathrm{NaCl}$, calculated from least-squares fit to a second-order polynomial of $1 / T_{\mathrm{m}}$ versus $\log \left[\mathrm{Na}^{+}\right]$(Figure 7), including the buffer contribution of $0.01 \mathrm{M} \mathrm{Na}^{+}$. ${ }^{d}$ Average from measurements with ascending and descending temperatures in the range $0.1-1.0 \mathrm{M} \mathrm{NaCl}$. 'Determined by using the given $T_{\mathrm{m}}$ in $0.1 \mathrm{M} \mathrm{NaCl}$ and the average $\Delta H_{\mathrm{vH}}$ for $\mathrm{NaCl}$

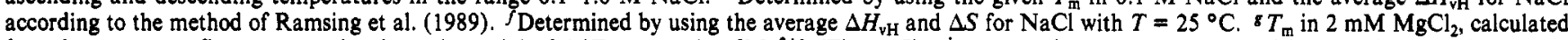
from least-squares fit to a second-order polynomial of $1 / T_{\mathrm{m}}$ versus $\log \left[\mathrm{Mg}^{2+}\right]$ (Figure 7). ${ }^{h}$ Average from measurements with ascending and descending temperatures in the range $0.5-8 \mathrm{mM} \mathrm{MgCl}{ }_{2}$.' Determined by using the given $T_{\mathrm{m}}$ in $2 \mathrm{mM} \mathrm{MgCl}_{2}$ and the average $\Delta H_{\mathrm{yH}}$ for $\mathrm{MgCl}_{2}$ according to the method of Ramsing et al. (1989). 'Determined by using the average $\Delta H_{\mathrm{vH}}$ and $\Delta S$ for $\mathrm{MgCl}_{2}$ with $T=25^{\circ} \mathrm{C}$.

namic properties and (ii) at any given $\mathrm{NaCl}$ or $\mathrm{MgCl}_{2}$ concentration, the $T_{\mathrm{m}} \mathrm{s}$ of the ps duplexes were $13-18^{\circ} \mathrm{C}$ lower than that of the corresponding aps molecule, a difference comparable to that observed with the $21-\mathrm{nt} \mathrm{C}$ series (Ramsing \& Jovin, 1988) but greater than the $10^{\circ} \mathrm{C}$ difference in the case of the ps and aps hairpins (van de Sande et al., 1988; Ramsing et al., 1989). In $2 \mathrm{mM} \mathrm{MgCl} 2$, the $T_{\mathrm{m}}$ values for the ps and aps duplexes were approximately the same as those obtained in $0.2-0.3 \mathrm{M} \mathrm{NaCl}$ (Figure 7). Added $\mathrm{NaCl}$ produced only a slightly destabilizing effect on the ps duplex, as observed previously with the C-series duplexes.

The $T_{\mathrm{m}}$ values of both the ps and aps duplexes showed a similar dependence on $\mathrm{NaCl}$ and $\mathrm{MgCl}_{2}$ concentration (Figure
7) in accordance with counterion condensation theory (Anderson \& Record, 1982). However, the relationship between reciprocal $T_{\mathrm{m}}$ and $\log$ [salt] was not strictly linear. The slope decreased above $\sim 0.5 \mathrm{M} \mathrm{NaCl}$ or $1 \mathrm{mM} \mathrm{MgCl}_{2}$, regions in which the predictions of the counterion condensation theory are no longer valid; a strictly linear dependence of $1 / T_{\mathrm{m}}$ on $\log \left[\mathrm{Na}^{+}\right]$is to be expected only for $\left[\mathrm{Na}^{+}\right]<0.5 \mathrm{M}$, even if activity coefficients are taken into account. Above this value, $T_{\mathrm{m}}$ passes through a maximum and then decreases with further increase of $\left[\mathrm{Na}^{+}\right]$(Anderson \& Record, 1982). The salt dependence of the helix-coil transitions of polyelectrolytes such as DNA in the molar range is described more adequately by the theory based on potentials of mean force (Garcia \& 


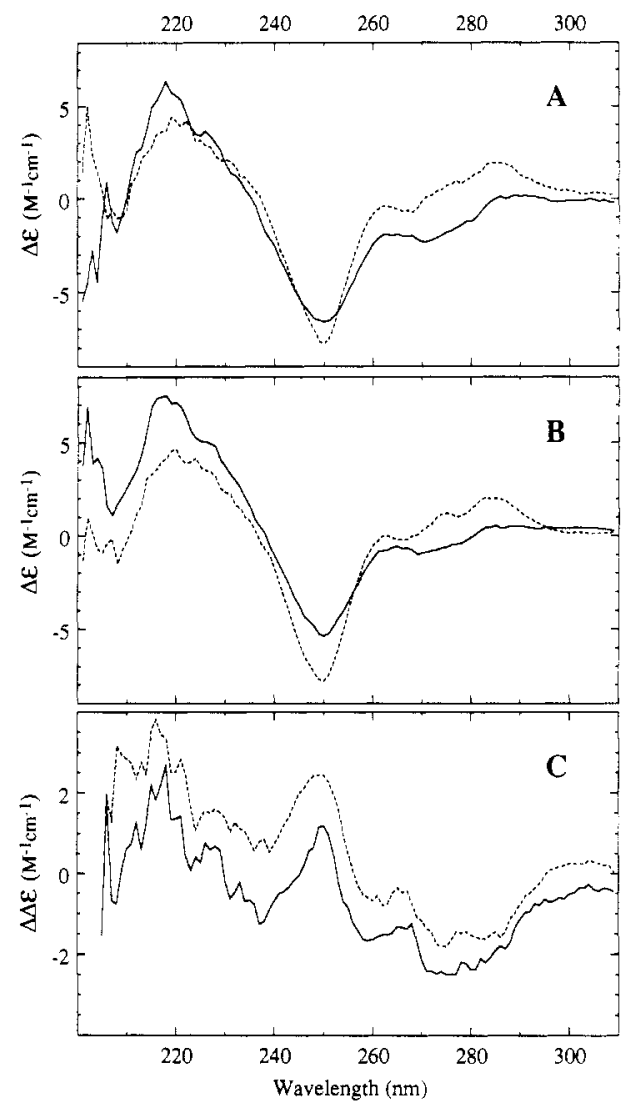

FIGURE 5: Circular dichroism spectra of ps-D3.D4 and aps-D2.D4. (A) $2 \mathrm{mM} \mathrm{MgCl}$ at $15^{\circ} \mathrm{C}$, ps-D3.D4 (-) and aps-D2.D4 (--). (B) $0.1 \mathrm{M} \mathrm{NaCl}$ at $15^{\circ} \mathrm{C}$, ps-D3.D4 (-) and aps-D2.D4 (-.). (C) Difference spectra (ps - aps) at $15^{\circ} \mathrm{C}$ in $2 \mathrm{mM} \mathrm{MgCl}_{2}(-)$ and in $0.1 \mathrm{M} \mathrm{NaCl}(--)$.
Soumpasis, 1988; unpublished data).

To establish a correlation between $1 / T_{\mathrm{m}}$ versus $\log$ [salt] valid at higher salt concentrations, the data were fitted by regression to a second-order polynomial (Figure 7). The values of $1 / T_{\mathrm{m}}$ were also plotted against $\log$ (activity $\left[\mathrm{Na}^{+}\right]$) with the activity calculated according to the method of Gibbard et al. (1974). The resultant plots revealed a decreased slope above $\sim 0.5 \mathrm{M} \mathrm{NaCl}$ as well, with the regression line only shifted by a more or less constant value (the calculated activity coefficients were in the range $0.91-0.82$ ) from the corresponding plot of $1 / T_{\mathrm{m}}$ versus $\log \left[\mathrm{Na}^{+}\right]$.

The values for $\Delta H_{\mathrm{vH}}$ were significantly lower $(\sim 25 \%)$ for the ps compared to the aps helices (Table I), being in good agreement with the determinations for the $\mathrm{C}$ series (Ramsing \& Jovin, 1988; Ramsing et al, 1989). The free energy difference $\Delta G$ between the 25 -nt ps and aps duplexes is about $35 \mathrm{~kJ} \mathrm{~mol}^{-1}$ under standard conditions (Table I). The enthalpy change per mole of nearest-neighbor interaction $\Delta h$ (in our case, $n-1=24$ interactions/duplex), evaluated under the conditions of maximal stability, i.e., in $\mathrm{MgCl}_{2}$, was $21 \mathrm{~kJ} \mathrm{~mol}^{-1}$ for ps-D1.D2, $23 \mathrm{~kJ} \mathrm{~mol}^{-1}$ for ps-D3.D4, $31 \mathrm{~kJ} \mathrm{~mol}^{-1}$ for aps D1.D3, and $28 \mathrm{~kJ} \mathrm{~mol}^{-1}$ for aps-D2.D4. The thermodynamic parameters are summarized in Table $\mathrm{I}$.

Examination of the two ps and aps combinations indicated slight differences in the experimental $\Delta H_{\mathrm{vH}}$ within the two groups, the tendencies being the same in both $\mathrm{NaCl}$ and $\mathrm{MgCl}_{2}$ (Table I). In the case of the aps duplexes, discrepancies were expected because the molecules are not equivalent with respect to their nearest-neighbor interactions: aps-D1.D3 has four AT/TA and three TA/AT pairs, whereas aps-D2.D4 has three AT/TA and four TA/AT pairs, seen in the $5^{\prime} \rightarrow 3^{\prime}$ direction. From the studies of Breslauer et al. (1986) on B-DNA oligonucleotides one would predict a higher value $(\sim 2 \%)$ for the
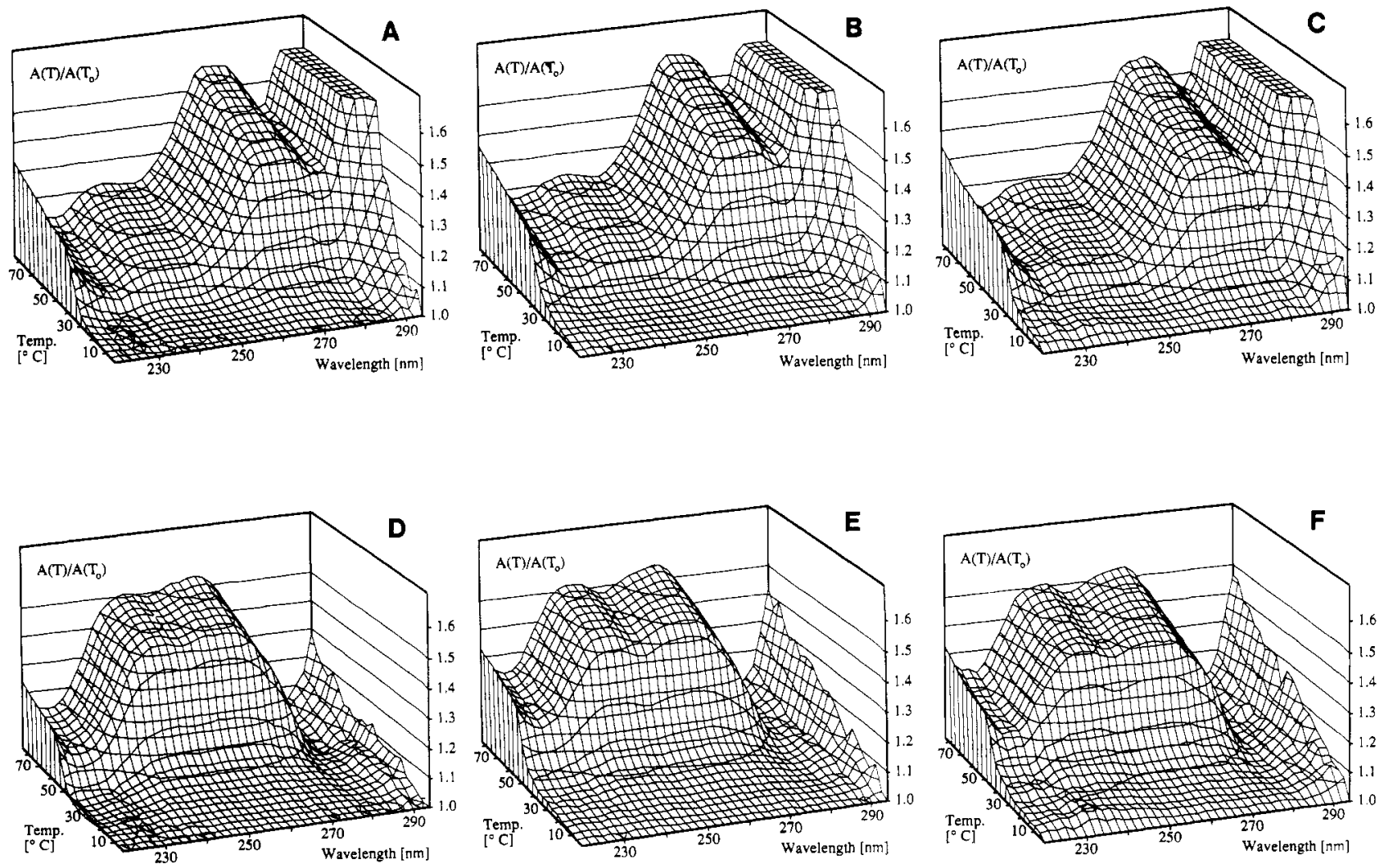

FIGURE 6: Thermally resolved ultraviolet absorption spectra of ps and aps helices expressed as the hyperchromicity, the ratio $A_{\lambda}(T) / A_{\lambda}\left(T_{0}\right)$, where $T_{0}$ is the initial temperature. (Top row) Parallel-stranded DNAs (A) ps-D1.D2 in $2 \mathrm{mM} \mathrm{MgCl}$, (B) ps-D3.D4 in $2 \mathrm{mM}$ MgCl ${ }_{2}$, and (C) ps-D3.D4 in $0.1 \mathrm{M} \mathrm{NaCl}$. (Bottom row) Antiparallel-stranded DNAs (D) aps-D1.D3 in $2 \mathrm{mM} \mathrm{MgCl}{ }_{2}$, (E) aps-D2.D4 in $2 \mathrm{mM} \mathrm{MgCl}$, and $(F)$ aps-D2.D4 in $0.1 \mathrm{M} \mathrm{NaCl}$. 

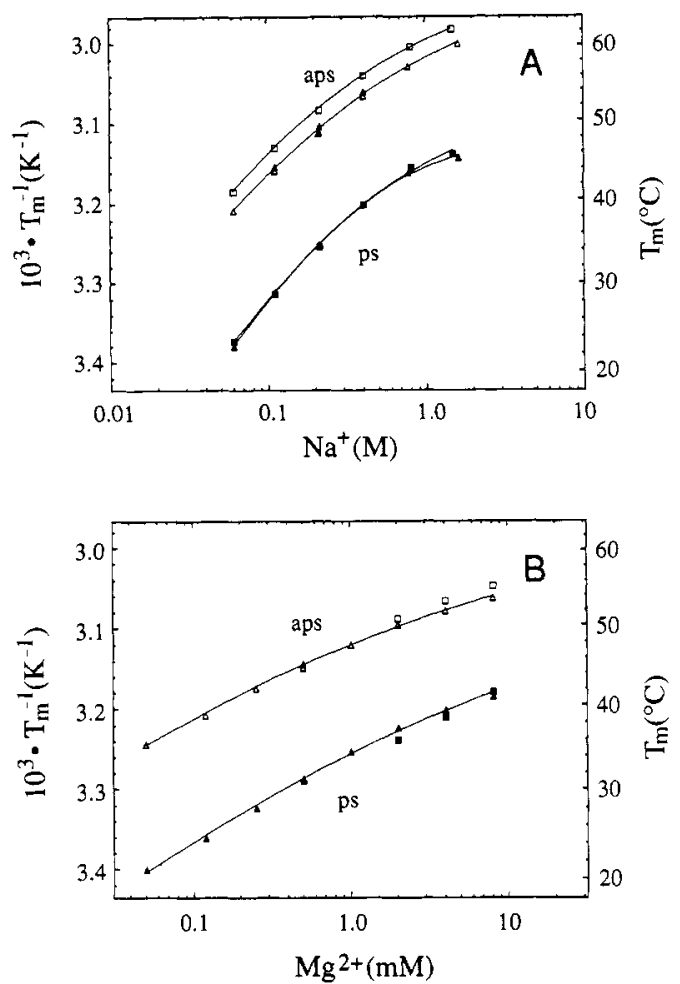

FIGURE 7: Melting temperature of the helix-coil transition of $p s$ and aps duplexes as a function of the type and concentration of added

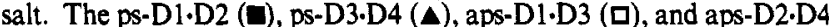
$(\Delta)$ duplexes are depicted. The solid lines are a regression in the form $1 / T_{\mathrm{m}}=c_{0}+c_{1} \log$ [salt] $+c_{2}(\log$ [salt $\left.]\right)^{2} . T_{\mathrm{m}}$ values have been corrected to a DNA concentration of $1.6 \mu \mathrm{M}$ strands (Ramsing et al., 1989). (A) $1 / T_{\mathrm{m}}$ versus $\log \left[\mathrm{Na}^{+}\right]$. The $\mathrm{Na}^{+}$concentration includes the buffer contribution. ps-D1.D2 $c_{0}=3.149 \times 10^{-3}, c_{1}=$ $-1.049 \times 10^{-4}, c_{2}=6.511 \times 10^{-5} ; \mathrm{ps}-\mathrm{D} 3 \cdot \mathrm{D} 4 c_{0}=3.153 \times 10^{-3}, c_{1}$ $=-8.653 \times 10^{-5}, c_{2}=8.150 \times 10^{-5} ;$ aps-D1.D3 $c_{0}=2.995 \times 10^{-3}$, $c_{1}=-9.168 \times 10^{-5}, c_{2}=5.056 \times 10^{-5} ;$ aps-D2.D4 $c_{0}=3.019 \times 10^{-3}$, $c_{1}=-1.102 \times 10^{-4}, c_{2}=3.831 \times 10^{-5}$. (B) $1 / T_{\mathrm{m}}$ versus $\log \left[\mathrm{Mg}^{2+}\right]$. ps-D1.D2 $c_{0}=3.263 \times 10^{-3}, c_{1}=-7.807 \times 10^{-5}, c_{2}=-1.656 \times 10^{-5}$; ps-D3.D4 $c_{0}=3.256 \times 10^{-3}, c_{1}=-9.674 \times 10^{-5}, c_{2}=1.277 \times 10^{-5}$; aps-D1.D3 $c_{0}=3.110 \times 10^{-3}, c_{1}=-7.807 \times 10^{-5}, c_{2}=5.519 \times 10^{-6}$; aps-D2.D4 $c_{0}=3.120 \times 10^{-3}, c_{1}=-7.855 \times 10^{-5}, c_{2}=1.353 \times 10^{-5}$.

$\Delta H_{\mathrm{vH}}$ of aps-D1.D3 compared to that of aps-D2.D4. In accordance with this expectation, aps-D1·D3 exhibits a greater thermodynamic stability than aps-D2.D4, as reflected in the respective $\Delta H_{\mathrm{vH}}$ and $T_{\mathrm{m}}$ values (Figure 7; Table I). However, the magnitudes of the differences are greater than those calculated from the reported (Breslauer et al, 1986) nearest-neighbor interaction enthalpies. In contrast, the ps-D1.D2 and ps-D3.D4 duplexes have the same distribution of nearest neighbors because their sequences are simply inverted. They can be considered to be equivalent in thermodynamic stability as judged from the virtually identical salt-dependent melting temperatures (Figure 7). Thus, both sets of molecules exhibit internally consistent properties and serve to establish the quantitative distinctions between ps and aps DNA.

\section{CONCLUDING REMARKS}

The thermodynamic properties of all ps (and corresponding aps) DNA molecules we have studied to date are compared extensively elsewhere (Ramsing et al., 1989). It appears so far that the properties of ps-DNA containing A.T base pairs exclusively are not greatly dependent on the precise sequence, e.g., whether homopolymeric or mixed. The database is as yet too small to derive precise values for the various nearest-neighbor interactions, as has been done in the case of B-DNA (Breslauer et al., 1986). Numerous other studies with the D-series duplexes have been carried out: (i) The D series of ps-DNA molecules shares the drug-binding properties of the C-series duplexes (Ramsing \& Jovin, 1988) and hairpin molecules (van de Sande et al., 1988). The bis(benzimidazole) drug Hoechst 33258 and 4',6-diamidino-2-phenylindole (DAPI), which bind in the minor groove of B-DNA, exhibit little fluorescence with the ps molecules compared to that obtained with the aps molecules. In contrast to this finding, the intercalator ethidium bromide forms with ps-DNA a complex that has higher fluorescence than that of its aps counterpart. The thermodynamic, spectral, and excited-state lifetime data for such complexes will be reported elsewhere. (ii) The ${ }^{31} \mathrm{P}$ NMR spectra have been determined and demonstrate dramatic differences between the ps and aps duplexes (K. Rippe, N. B. Ramsing, F. Eckstein, and T. M. Jovin, unpublished data). (iii) The relative functional properties of the $\mathrm{D}$ series of $\mathrm{ps}$ and aps duplexes as substrates for a number of DNA-dependent enzymes and chemical reagents have been examined in a companion study (Rippe \& Jovin, 1989). (iv) The biological significance of ps-DNA depends upon the potential for its formation with natural sequences. We have constructed variants of the D series in which four $A$ ( $T$ in the complementary oligonucleotide) residues have been replaced with $\mathrm{G}$ and $\mathrm{C}$, respectively. These molecules still adopt the ps conformation, albeit with lower thermodynamic stability (K. Rippe, N. B. Ramsing, R. Klement, and T. M. Jovin, unpublished data).

\section{ACKNOWLEDGMENTS}

We thank G. Heim for excellent technical assistance.

Registry No. D1, 123411-18-7; D2, 123411-19-8; D3, 123411-20-1; D4, 123411-21-2; ps-D1.D2, 123411-22-3; ps-D3.D4, 123411-23-4; aps-D1-D3, 123411-24-5; aps-D2-D4, 123411-25-6; aps-D1-D1, 123411-26-7; $\mathrm{NaCl}, 7647-14-5 ; \mathrm{MgCl}_{2}, 7786-30-3$.

\section{REFERENCES}

Anderson, C. F., \& Record, M. T., Jr. (1982) Annu. Rev. Phys. Chem. 33, 191-222.

Breslauer, K. J., Frank, R., Blöcker, H., \& Marky, L. A. (1986) Proc. Natl. Acad. Sci. U.S.A. 83, 3746-3750.

Garcia, A. E., \& Soumpasis, D. M. (1988) Biophys. J. 53, $43 a$.

Germann, M. W., Kalish, B. W., \& van de Sande, J. H. (1988) Biochemistry 27, 8302-8306.

Gibbard, H. F., Jr., Scatchard, G., Rousseau, R. A., \& Creek, J. L. (1974) J. Chem. Eng. Data 19, 281-288.

Pattabiraman, N. (1986) Biopolymers 25, 1603-1606.

Ramsing, N. B., \& Jovin, T. M. (1988) Nucleic Acids Res. 16, 6659-6676.

Ramsing, N. B., Rippe, K., \& Jovin, T. M. (1989) Biochemistry (first of three papers in this issue).

Riley, M., Maling, B., \& Chamberlin, M. J. (1966) J. Mol. Biol. 20, 359-389.

Rippe, K., \& Jovin, T. M. (1989) Biochemistry (third of three papers in this issue).

Saenger, W. (1984) in Principles of Nucleic Acid Structure, Springer-Verlag, New York.

van de Sande, J. H., Ramsing, N. B., Germann, M. W., Elhorst, W., Kalisch, B. W., v. Kitzing, E., Pon, R. T., Clegg, R. M., \& Jovin, T. M. (1988) Science 241, 551-557. 